\title{
Visual acuity in fish consumers of the Brazilian Amazon: risks and benefits from local diet
}

\author{
Myriam Fillion ${ }^{1}$, Mélanie Lemire ${ }^{2,1}$, Aline Philibert ${ }^{1}$, Benoît Frenette $^{3}$, \\ Hope Alberta Weiler ${ }^{4}$, Jason Robert Deguire ${ }^{4}$, Jean Remy Davée Guimarães ${ }^{5}$, \\ Fabrice Larribe ${ }^{6}$, Fernando Barbosa $\mathrm{Jr}^{7}$ and Donna Mergler ${ }^{1, *}$ \\ ${ }^{1}$ Centre de recherche interdisciplinaire sur la biologie, la santé, la société et l'environnement (Cinbiose), \\ Université du Québec à Montréal, C.P. 8888, Succ. Centre-Ville, Montréal, Canada H3C 3P8: ${ }^{2}$ Axe santé des \\ populations et environnementale, Centre de Recherche du Centre hospitalier universitaire de Québec (CHUQ), \\ Québec, Canada: ${ }^{3}$ École d'Optométrie, Université de Montréal, Montréal, Canada: ${ }^{4}$ School of Dietetics and \\ Human Nutrition, McGill University, Ste-Anne-de-Bellevue, Canada: ${ }^{5}$ Laboratório de Traçadores, Instituto de \\ Biofísica, Universidade Federal do Rio de Janeiro, Rio de Janeiro, Brasil: 'Département de mathématiques, \\ Université du Québec à Montréal, Montréal, Canada: ${ }^{7}$ Laboratório de Toxicologia e Essencialidade de Metais, \\ Departamento de Análises Clínicas, Toxicológicas e Bromatológicas, Faculdade de Ciências Farmacêuticas \\ de Ribeirão Preto, Universidade de São Paulo, Ribeirão Preto, Brasil
}

Submitted 22 February 2011: Accepted 8 June 2011: First published online 6 September 2011

\begin{abstract}
Objective: To examine the associations between near and distant visual acuity and biomarkers of $\mathrm{Hg}, \mathrm{Pb}, n-3$ fatty acids and Se from the local diet of fish-eating communities of the Tapajós River in the Brazilian Amazon.

Design: Visuo-ocular health and biomarkers of $\mathrm{Hg}$ (hair, whole blood, plasma), $\mathrm{Pb}$ (whole blood), Se (whole blood and plasma) and $n$ - 3 fatty acids (plasma total phospholipids) were assessed in a cross-sectional study.

Setting: Lower Tapajós River Basin (State of Pará, Brazil), May to July 2006.

Subjects: Two hundred and forty-three adults ( $\geq 15$ years) without diagnosed agerelated cataracts or ocular pathologies.

Results: Near visual acuity was negatively associated with hair $\mathrm{Hg}$ and positively associated with \%DHA, with a highly significant $\log \mathrm{Hg} \times$ age interaction term. Stratifying for age showed that while young people presented good acuity, for those aged $\geq 40$ years, clinical presbyopia was associated with hair $\mathrm{Hg} \geq 15 \mu \mathrm{g} / \mathrm{g}$ $(\mathrm{OR}=3 \cdot 93,95 \% \mathrm{CI} 1 \cdot 25,14 \cdot 18)$ and \%DHA (OR $=0 \cdot 37,95 \%$ CI $0 \cdot 11,1 \cdot 11)$. A similar age-related pattern was observed for distant visual acuity in relation to blood $\mathrm{Pb}$, but the evidence was weaker.

Conclusions: These findings suggest that $\mathrm{Hg}$ and $\mathrm{Pb}$ may affect visual acuity in older persons, while DHA appears to be protective for near visual acuity loss. In this population, with little access to eye care, diet may have an important influence on visuo-ocular ageing.
\end{abstract}

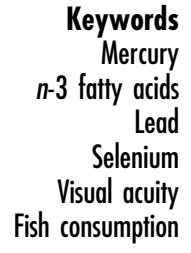

Methylmercury (MeHg) is a neurotoxic substance known to affect visual functions ${ }^{(1-3)}$. Visual impairments were studied in Japan, where people ingested contaminated fish following industrial releases of $\mathrm{Hg}$ and $\mathrm{MeHg}$ into Minamata Bay. Persons suffering from Minamata disease with cortical lesions showed restricted visual fields ${ }^{(4)}$ and impaired spatial contrast sensitivity ${ }^{(5)}$. However, Mukuno et $a l .{ }^{(5)}$ noted that visual acuity (VA) was not sensitive for detecting these cortical lesions.

More recent studies have looked at visual functions in adults exposed to lower levels of $\mathrm{MeHg}$ over their lifetime. In the Amazon, hair $\mathrm{Hg}$ levels were associated with acquired colour vision loss and reduced near visual contrast sensitivity, particularly in the middle and higher spatial frequencies ${ }^{(1,6)}$. In fish consumers of the St. Lawrence River region, acquired colour vision loss was linked to monoamine oxidase-B activity, which, in turn was negatively associated with blood $\mathrm{Hg}^{(7,8)}$. In these studies, VA was used as an independent variable to control for the possible effects of visual loss on the different visual functions.

In many areas of the Brazilian Amazon, fish is a dietary mainstay and fish-eating populations have among the highest $\mathrm{Hg}$ exposures observed today ${ }^{(9,10)}$. In this region, fish consumption is positively associated with $n$ - 3 fatty acids (FA) in plasma phospholipids (A Philibert, unpublished results). 
$n-3$ FA can have beneficial effects of on the adult and ageing visual system $^{(11-13)}$, notably for near VA ${ }^{(14)}$. DHA plays an important structural role in the eye and brain, where it can influence the physical nature of cell membranes, eicosanoid generation, cell signalling and gene expression ${ }^{(15)}$.

Other elements, identified in communities in the Brazilian Amazon, may likewise affect visual functions. Recently, elevated blood $\mathrm{Pb}$ levels were reported in communities of the Tapajós region ${ }^{(16)}$. A possible source is farinha, a flour derived from roasted manioc; $\mathrm{Pb}$ may be present in the roasting metal plates and incorporated into the farinha during the artisanal transformation ${ }^{(16)}$. In primates, $\mathrm{Pb}$ has been associated with diminished temporal visual function, with no evidence for accelerated decline in contrast sensitivity ${ }^{(17)}$.

Biomarkers of Se vary from normal to very high in this Amazonian region ${ }^{(18-20)}$; local foods, such as Brazil nuts, are naturally rich in $\mathrm{Se}^{(21)}$. Se may play a protective role in age-related eye diseases such as cataracts and maculopathies $^{(22-24)}$. In the Tapajós region, Se offsets Hg-related cataractogenesis $^{(23)}$. However, no studies have examined Se and VA.

The objective of the present study was to examine biomarkers of $\mathrm{Hg}, \mathrm{Pb}, n-3 \mathrm{FA}$ and $\mathrm{Se}$ in relation to near and distant VA in a fish-eating population from the Tapajós region of the Brazilian Amazon.

\section{Materials and methods}

\section{Study population}

The present study is part of an interdisciplinary project on $\mathrm{Hg}$ exposure and its effects on human health in the Lower Tapajós River Basin (State of Pará, Brazil; see Fig. 1) ${ }^{(25)}$. A cross-sectional study whose objective was to examine factors that may influence $\mathrm{Hg}$ toxicity was carried out from May to July 2006. A total of 448 participants were recruited in twelve communities using a convenience sampling procedure since it is difficult to apply a random sampling strategy in this setting ${ }^{(26)}$. Recruitment is described elsewhere ${ }^{(23)}$.

The study was approved by the Ethics Review Boards of the University of Quebec at Montreal, the Federal University of Rio de Janeiro and the Faculty of Pharmaceutical Sciences of the University of São Paulo-Ribeirão Preto. All participants signed an informed consent form, which was read to them. There was no remuneration for study participation.

\section{Sociodemographics and medical bistory}

An interview-administered questionnaire was used to collect information on sociodemographics, occupational and residential history. Dietary information was collected with a $7 \mathrm{~d} \mathrm{FFQ}^{(26)}$. A trained nurse administered the

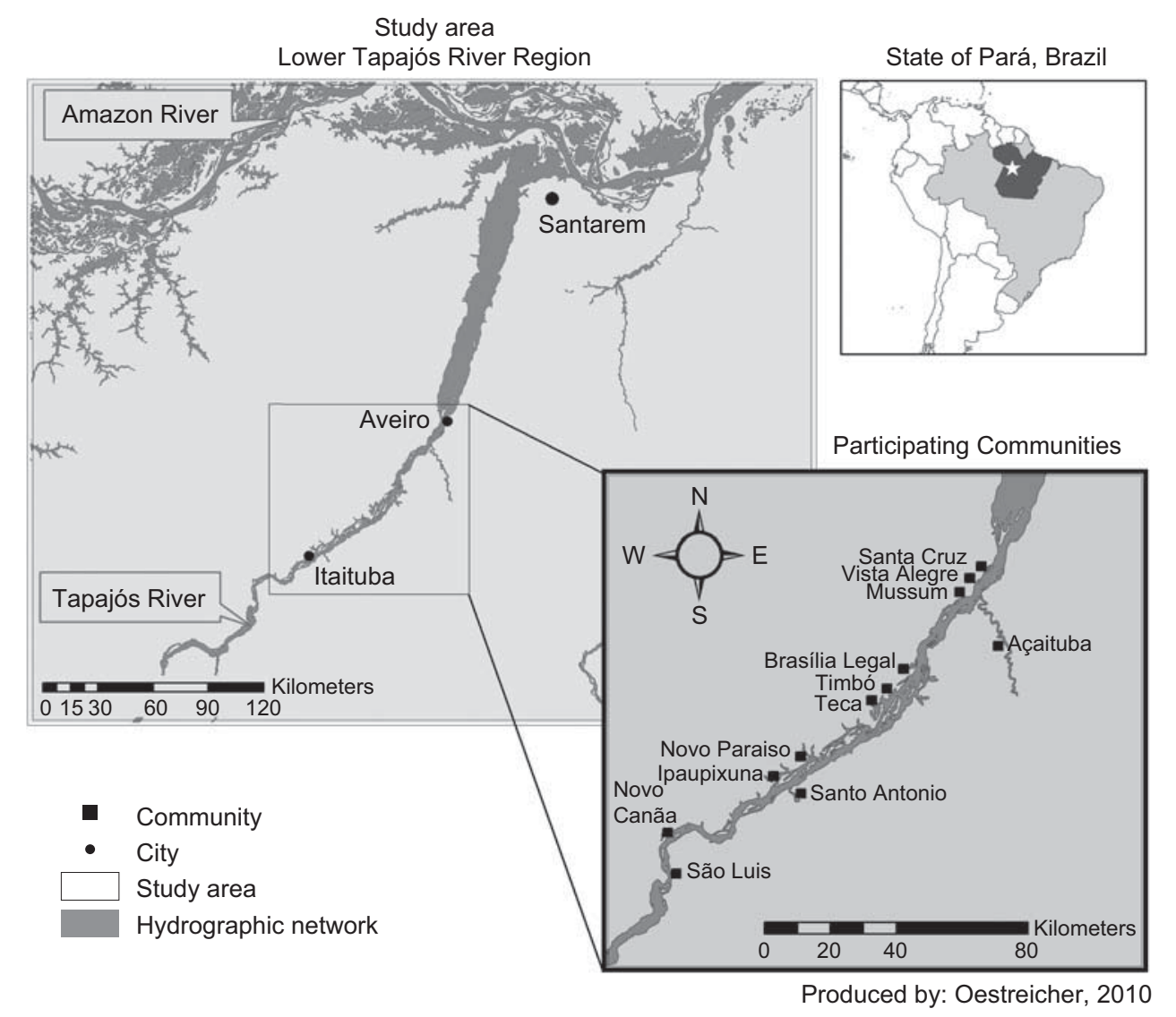

Fig. 1 Map of the study area showing the location of participating communities 
questionnaire on medical history. Current medication was noted. None of the interviewers were aware of the participants' exposure levels.

\section{Assessment of biomarkers of $\mathrm{Hg}, \mathrm{Pb}$ and Se}

\section{Hair}

Hair $\mathrm{Hg}$ has often been used as a biomarker for current and retrospective exposure ${ }^{(27)}$; it reflects $\mathrm{Hg}$ intake from fish consumption (for a review, see Mergler et al. ${ }^{(28)}$ ). Hair strands from the occipital region were cut at the root and stored in plastic bags. The first two centimetres from the root were used to determine total hair Hg concentration $(\mathrm{H}-\mathrm{Hg})$ by cold vapour atomic absorption spectrometry, according to the method described in Farant et al. ${ }^{(29)}$. Analyses were carried out at the laboratories of the First Nations and Inuit Health Laboratory of Health Canada (Ottawa, Canada). Analytical quality control was ensured with certified reference hair samples, provided by the Hair Mercury Inter-laboratory Comparison Program of Health Canada, Ottawa, Canada.

\section{Blood}

A Brazilian phlebotomist collected 6-ml blood samples in 'trace metal free' evacuated tubes (BD Vacutainer ${ }^{\circledR}$ ) containing heparin as anticoagulant. Total $\mathrm{Hg}$ in blood (B-Hg) and plasma (P-Hg), total $\mathrm{Pb}$ in blood (B-Pb) and total Se in blood (B-Se) and plasma (P-Se) were determined by inductively coupled plasma-mass spectrometry (Perkin Elmer DRC II). For Hg determination in whole blood and plasma, the method proposed by Palmer et $a l .{ }^{(30)}$ was adopted. For the other elements, the method proposed by Batista et al. ${ }^{(31)}$ was used. Samples were analysed at the Laboratório de Toxicologia e Essencialidade de Metais, Departamento de Análises Clínicas, Toxicológicas e Bromatológicas, Faculdade de Ciências Farmacêuticas de Ribeirão Preto, Universidade de São Paulo, Ribeirão Preto, Brazil. Quality control was guaranteed by analysing secondary reference materials, either provided by the New York State Department of Health's PT programme for trace elements in whole blood, or obtained from the external quality assessment scheme (EQAS) for trace elements operated by the Toxicology Center of the Quebec Public Health Institute (CTQ-INSP), Canada. Reference materials were analysed before and after ten ordinary samples.

\section{Plasma phospholipid fatty acid analysis}

Plasma total phospholipid FA were assessed for a subgroup of 349 people. For plasma separation, blood samples were centrifuged and pipetted into Eppendorf tubes previously cleaned in a class 100 clean room and immediately frozen at $-20^{\circ} \mathrm{C}$ before analysis. Total phospholipid FA were measured in plasma using a modified method of Bondia-Pons et al. ${ }^{(32)}$. Analyses were carried out at McGill University, Ste-Anne-de-Bellevue,
Canada. EPA and DHA were considered in the present study. The concentration of each phospholipid FA was expressed as an absolute concentration $(\mathrm{mg} / \mathrm{ml})$ and as a percentage of total plasma phospholipid FA.

\section{Visual functions assessment}

Visual and ocular health examinations were carried out by four optometrists from the School of Optometry of the University of Montreal, trained prior to the study to minimize inter-observer bias. None were involved in assessment of toxins or nutrients.

The anterior segment of the eye was examined using slit-lamp biomicroscopy. The posterior segment of the retina and its periphery were examined during pupillary dilation using two mydriatic agents (tropicamide $1 \% \mathrm{w} / \mathrm{v}$ and phenylephrine $2.5 \% \mathrm{w} / \mathrm{v}$ ). This procedure provided information on ocular pathologies for post hoc exclusion. The presence of pterygia, a corneal eye disease attributed to chronic UV-B exposure ${ }^{(33,34)}$, common in this region, was noted by the examiners.

Near and distant VA were assessed with the Allen and Tumbling E Charts, respectively for the right eye (OD) and the left eye (OS). For the purpose of statistical analysis, near and distant VA were log-transformed to obtain the minimum angle of resolution (Log MAR) to convert the geometric sequence of a traditional chart into a linear scale. The different functional categories for near and distant VA defined by the International Council of Ophthalmology ${ }^{(35)}$ are presented in Table 2. All examinations were made under the same conditions.

\section{Statistical analyses}

Descriptive statistics were used to illustrate the study population's general characteristics, the distribution of the biomarkers, as well as near and distant VA. Data normality was assessed with the Shapiro-Wilk $W$ test. Since exposure data and VA measures were skewed, both non-parametric (Wilcoxon/Kruskall-Wallis rank-sums test and Spearman's $\rho$ ) and parametric analyses (Student's $t$ and Pearson's $r$ correlation) were performed. When non-parametric and parametric results were in agreement, only the former are presented. For the multiple regression models, variables were log-transformed when necessary.

Multiple linear regressions were used to build five models for near and distant VA (Log MAR). The first model (M1) examined the relevant covariables: age, sex, smoking (yes $v$. no), drinking (yes $v$. no) and examiner (2 v. 1). In model 2 (M2), in addition to the previous covariables, we separately tested the biomarkers of $\mathrm{Hg}$ (B-Hg and $\mathrm{H}-\mathrm{Hg}$ ) and retained the one showing the strongest association (H-Hg). In model 3 (M3), we added B-Pb. In model 4 (M4), we retained the previous explanatory variables and separately tested EPA, DHA and EPA+DHA, as well as their percentage in the total plasma phospholipid FA (\%EPA, $\% \mathrm{DHA}$ and \%EPA+DHA). The $n-3$ FA variable with the strongest association (\%DHA) was retained in model 5 (M5), 
and we separately tested biomarkers of Se (B-Se and P-Se). Finally, model 6 (M6) included age, sex, smoking, drinking, examiner, $\mathrm{H}-\mathrm{Hg}, \mathrm{B}-\mathrm{Pb}, \% \mathrm{DHA}$ and B-Se. The contribution of pterygia was verified in each of the models. All models were tested for OD and OS; the results are presented for OD. Homoscedasticity was verified using Studentized residuals and outliers were excluded at $>|3|$.

Since delayed neurotoxicity has been demonstrated in animal studies ${ }^{(17)}$, the multiplicative interaction term between age and $\mathrm{Hg}$ was likewise tested. The multiplicative interaction terms between $\mathrm{Hg}$ and $\mathrm{Se}, \mathrm{Hg}$ and $\mathrm{Pb}$ and $\mathrm{Hg}$ and $n$-3 FA were also tested. The only significant interaction term was age $\times$ Log $\mathrm{H}-\mathrm{Hg}$. Data were stratified with respect to age category and the above multiple linear regression models were re-run.

For those over 40 years of age, multivariate logistic regression models (OR and $95 \% \mathrm{CI}$ ) were used to examine the associations between near and distant visual impairment and biomarkers of $\mathrm{Hg}, \mathrm{Pb}, \mathrm{Se}$ and $n-3 \mathrm{FA}$. $\mathrm{H}-\mathrm{Hg}$ was categorized at $15 \mu \mathrm{g} / \mathrm{g}$ and $\mathrm{B}-\mathrm{Pb}$ at $10 \mu \mathrm{g} / \mathrm{dl}$, while Se was categorized at the median and $n-3$ FA at the first tertile. Age, sex, current smoking habit (yes $v$. no), alcohol consumption (yes $v$. no) and examiner were included in all of the models.

Results were defined as statistically significant at $P<0 \cdot 05$. Analyses were performed using the statistical software packages JMP version $8 \cdot 0 \cdot 1$ (SAS Institute Inc., Cary, NC, USA) and SPSS version 16.0 (SPSS Inc., Chicago, IL, USA).

\section{Results}

The analyses considered 349 people for whom there were complete data on exposure and FA. Near and distant VA were not available in at least one eye for sixteen and four persons, respectively. Persons reporting health conditions, diseases or medications considered as possible aetiological factors for poor near and distant VA or influencing $\mathrm{Hg}$ and/or Se metabolism were excluded from the analyses: pregnancy $(n 5)$, breast-feeding ( $n 5$ ), reported diagnosed diabetes ( $n$ 5), psychotropic drugs ( $n$ 5), reported cerebrovascular accident ( $n$ 11). Further exclusions were made with respect to diagnosed eye pathology in either eye ( $n 21$ for OD and $n 23$ for OS). Cataracts were diagnosed in forty-five people, who were likewise excluded from the analyses.

Analyses considered 243 persons whose sociodemographic characteristics are presented in Table 1. Alcohol, mostly beer, was consumed mainly during the weekend and on special occasions. Significantly more men reported drinking than women $(73.5 \%$ v. $48.4 \%, P<0.0001)$. Among smokers, cigarette consumption was low (median:

Table 1 Sociodemographic characteristics, biomarkers of exposure, nutrients and visual acuity among the study population: adults ( $n$ 243) from fish-eating communities of Tapajós River in the Brazilian Amazon

\begin{tabular}{|c|c|c|c|c|c|c|}
\hline Characteristic & $n$ & $\%$ & Mean & SD & Median & Range \\
\hline Women & 126 & $51 \cdot 9$ & & & & \\
\hline Men & 117 & $48 \cdot 1$ & & & & \\
\hline Age (years) & & & $35 \cdot 9$ & $12 \cdot 3$ & $35 \cdot 0$ & $15-66$ \\
\hline Education (years) & & & $5 \cdot 8$ & $3 \cdot 4$ & $4 \cdot 0$ & $0-16$ \\
\hline Alcohol drinkers & 147 & $60 \cdot 5$ & & & & \\
\hline Current smokers & 54 & $22 \cdot 0$ & & & & \\
\hline $\mathrm{H}-\mathrm{Hg}(\mu \mathrm{g} / \mathrm{g})$ & & & $14 \cdot 4$ & $10 \cdot 5$ & $11 \cdot 5$ & $1 \cdot 0-57 \cdot 9$ \\
\hline $\mathrm{B}-\mathrm{Hg}(\mu \mathrm{g} / \mathrm{l})$ & & & $51 \cdot 6$ & $37 \cdot 0$ & $41 \cdot 8$ & $1 \cdot 7-179 \cdot 3$ \\
\hline P-Hg $(\mu g / l)$ & & & $8 \cdot 0$ & $6 \cdot 5$ & $6 \cdot 9$ & $0 \cdot 2-30.9$ \\
\hline B-Se $(\mu \mathrm{g} / \mathrm{l})$ & & & $313 \cdot 4$ & $215 \cdot 5$ & $250 \cdot 6$ & $103 \cdot 3-1500 \cdot 2$ \\
\hline P-Se $(\mu g / l)$ & & & $178 \cdot 8$ & $120 \cdot 1$ & $141 \cdot 3$ & $53 \cdot 6-913 \cdot 2$ \\
\hline $\mathrm{B}-\mathrm{Pb}(\mu \mathrm{g} / \mathrm{dl})$ & & & $12 \cdot 6$ & $8 \cdot 2$ & $10 \cdot 4$ & $0 \cdot 6-48 \cdot 3$ \\
\hline EPA $(\mathrm{mg} / \mathrm{ml})$ & & & 0.006 & 0.004 & 0.005 & $0.0-0.022$ \\
\hline$\%$ EPA (\% of total plasma phospholipid FA) & & & 0.44 & $0 \cdot 23$ & 0.44 & $0-1 \cdot 19$ \\
\hline $\mathrm{DHA}(\mathrm{mg} / \mathrm{ml})$ & & & 0.024 & 0.014 & 0.02 & $0.003-0.085$ \\
\hline$\%$ DHA (\% of total plasma phospholipid FA) & & & 1.98 & $0 \cdot 74$ & $1 \cdot 90$ & $0 \cdot 33-4 \cdot 39$ \\
\hline $\mathrm{EPA}+\mathrm{DHA}(\mathrm{mg} / \mathrm{ml})$ & & & 0.03 & 0.02 & $0 \cdot 027$ & $0 \cdot 003-0 \cdot 10$ \\
\hline$\%(E P A+D H A)$ ( $\%$ of total plasma phospholipid FA) & & & $2 \cdot 41$ & $0 \cdot 89$ & $2 \cdot 40$ & $0 \cdot 43-5 \cdot 22$ \\
\hline \multicolumn{7}{|l|}{ Near visual acuity } \\
\hline OD, Log MAR units & & & 0.36 & $0 \cdot 22$ & $0 \cdot 18$ & $0-1$ \\
\hline OS, Log MAR units & & & 0.37 & $0 \cdot 26$ & $0 \cdot 18$ & $0 \cdot 18-1$ \\
\hline \multicolumn{7}{|l|}{ Distant visual acuity } \\
\hline OD, Log MAR units & & & 0.09 & $0 \cdot 21$ & 0.00 & $-0 \cdot 13-1$ \\
\hline OS, Log MAR units & & & $0 \cdot 10$ & $0 \cdot 25$ & 0.00 & $-0 \cdot 13-1 \cdot 3$ \\
\hline \multicolumn{7}{|l|}{ Moderate near visual impairment } \\
\hline OD & 62 & $25 \cdot 6$ & & & & \\
\hline OS & 63 & $26 \cdot 0$ & & & & \\
\hline \multicolumn{7}{|l|}{ Moderate distant visual impairment } \\
\hline OD & 16 & $6 \cdot 6$ & & & & \\
\hline OS & 16 & $6 \cdot 6$ & & & & \\
\hline
\end{tabular}

$\mathrm{H}$, hair; $\mathrm{B}$, blood; $\mathrm{P}$, plasma; $\mathrm{FA}$, fatty acids; OD, right eye; OS, left eye; MAR, minimum angle of resolution. 
Table 2 Near and distant visual acuity and their functional category in the right eye among adults ( $n$ 243) from fish-eating communities of Tapajós River in the Brazilian Amazon

\begin{tabular}{|c|c|c|c|c|c|c|}
\hline \multirow[b]{2}{*}{ Visual acuity } & \multirow[b]{2}{*}{ Log MAR } & \multirow[b]{2}{*}{ ICO category } & \multicolumn{2}{|c|}{$<40$ years old } & \multicolumn{2}{|c|}{$\geq 40$ years old } \\
\hline & & & $n$ & $\%$ & $n$ & $\%$ \\
\hline \multicolumn{7}{|l|}{ a) Near visual acuity } \\
\hline $6 / 3 \cdot 8-6 / 7 \cdot 5$ & $-0 \cdot 1-0 \cdot 1$ & Normal vision & 133 & $85 \cdot 8$ & 13 & $14 \cdot 1$ \\
\hline $6 / 9 \cdot 5-6 / 18$ & $0.2-0.5$ & Mild vision loss & 18 & $11 \cdot 6$ & 41 & $44 \cdot 6$ \\
\hline 6/24-6/48 & $0.6-0.9$ & Moderate vision loss & 2 & $1 \cdot 3$ & 18 & $19 \cdot 6$ \\
\hline $6 / 60-3 / 60$ & $1 \cdot 0-1 \cdot 3$ & Severe vision loss & 2 & $1 \cdot 3$ & 14 & $15 \cdot 2$ \\
\hline $2 / 60$ & $1 \cdot 4-1 \cdot 7$ & Profound vision loss & 0 & & 6 & $6 \cdot 5$ \\
\hline $1 / 60$ and less & $1 \cdot 8-2 \cdot 0$ & Near blindness & 0 & & 0 & \\
\hline No light perception & $\mathrm{N} / \mathrm{A}$ & Blindness & 0 & & 0 & \\
\hline \multicolumn{7}{|c|}{ b) Distant visual acuity } \\
\hline $6 / 3 \cdot 8-6 / 7 \cdot 5$ & $-0 \cdot 1-0 \cdot 1$ & Normal vision & 140 & $88 \cdot 1$ & 42 & $44 \cdot 7$ \\
\hline 6/9.5-6/18 & $0.2-0.5$ & Mild vision loss & 15 & $9 \cdot 4$ & 39 & 41.5 \\
\hline 6/24-6/48 & $0.6-0.9$ & Moderate vision loss & 2 & $1 \cdot 3$ & 12 & $12 \cdot 8$ \\
\hline 6/60-3/60 & $1 \cdot 0-1 \cdot 3$ & Severe vision loss & 2 & $1 \cdot 3$ & 1 & $1 \cdot 1$ \\
\hline $2 / 60$ & $1 \cdot 4-1 \cdot 7$ & Profound vision loss & 0 & & 0 & \\
\hline $1 / 60$ and less & $1 \cdot 8-2 \cdot 0$ & Near blindness & 0 & & 0 & \\
\hline No light perception & N/A & Blindness & 0 & & 0 & \\
\hline
\end{tabular}

MAR, minimum angle of resolution; ICO, International Council of Ophthalmology; N/A, not applicable.

8.7 cigarettes/d). There was no association between age and alcohol or tobacco consumption. Most (90\%) had eaten at least one fish meal in the week preceding the interview.

Mean and median values of the biomarkers are presented in Table $1 . \mathrm{H}-\mathrm{Hg}$ concentrations were higher in men than in women (median $14.3 v .9 \cdot 4 \mu \mathrm{g} / \mathrm{g}$, Wilcoxon $\left.\chi^{2} P<0 \cdot 0001\right)$ and $\mathrm{H}-\mathrm{Hg}$ levels tended to increase with age (Spearman's $\rho=0 \cdot 117, P=0 \cdot 07$ ). B-Se was similar in men and women men and age did not influence $\mathrm{B}-\mathrm{Se}$ status. $\mathrm{B}-\mathrm{Pb}$ was higher in men than in women $\left(14 \cdot 4 v \cdot 7 \cdot 3 \mu \mathrm{g} / \mathrm{dl}\right.$, Wilcoxon $\left.\chi^{2} P<0 \cdot 0001\right)$ and tended to increase with age (Spearman's $\rho=0 \cdot 111, P=0 \cdot 08$ ). All $n$-3 FA biomarkers were positively associated with age (Wilcoxon $\chi^{2} P<0 \cdot 0001$ ) and were similar for men and women, except for the sum of EPA and DHA, which was significantly lower in men than in women (median: 0.024 v. $0 \cdot 031 \mathrm{mg} / \mathrm{ml}$, Wilcoxon $\left.\chi^{2} P=0 \cdot 03\right)$.

Participants excluded for age-related cataracts were older than the participants included in the analyses (median: 58.5 v. 35.9 years, $P<0.0001$ ). Indeed, the oldest study subjects here were 66 years old. As expected, both near and distant VA were better in participants compared with those excluded. Biomarkers of $\mathrm{Hg}, \mathrm{Pb}$ and $n$-3 FA were similar in both groups, but B-Se was significantly lower in the excluded group (median: 202.6 $v$. $250 \cdot 6 \mu \mathrm{g} / \mathrm{l}, P<0 \cdot 0001)$.

Near VA was similar for men and women in both eyes and decreased with age (OD: Spearman's $\rho=0 \cdot 805$, $P<0 \cdot 0001$; OS: Spearman's $\rho=0 \cdot 753, P<0 \cdot 0001)$. Distant VA was the same for men and women and likewise decreased with age (OD: $\rho=0.5630, P<0.0001$; OS: $\rho=0.5925, P<0.0001)$. Approximately $25 \%$ of the study group presented moderate near VA impairment, and $7 \%$ moderate distant VA impairment (Table 1). Pterygia was observed in at least one eye in eighty-seven persons (36\%).
The classification of VA according to functional category differed between age groups (Table 2). Most of those under 40 years (85\%) presented near VA in the normal range, while for the older group ( 40 to 66 years) it was the inverse: $85.9 \%$ had mild to profound near visual loss. For distant VA, $13 \%$ of the younger group presented mild to severe vision loss, while $55 \%$ of the older group were in these categories. Pterygia was likewise more prevalent in the older persons compared with the younger ( $53 \%$ v. $26 \%, P<0 \cdot 0001)$.

The associations between near VA and the relevant covariables and biomarkers are presented in Table 3a. In the first model (M1), which contains only the covariables, age was strongly and positively associated with near VA loss. When Log H-Hg was added to the model (M2), it was likewise positively associated with near VA loss. In the following models (M3 to M6), \%DHA showed a negative association with near VA loss but Log B-Pb and Log B-Se did not show any association with the outcome. When \%DHA was included in the model, the $\beta$ estimate for Log $\mathrm{H}-\mathrm{Hg}$ increased by almost $30 \%$. The interaction term age $\times$ Log $\mathrm{H}-\mathrm{Hg}$ was highly significant $(P=0 \cdot 002)$.

Since there was a highly significant interaction between age and $\log \mathrm{H}-\mathrm{Hg}$, results were stratified by age at 40 years old. No association was observed between Log $\mathrm{H}-\mathrm{Hg}$ and near VA loss in younger people, whereas for older persons, there was a highly significant association with Log $\mathrm{H}-\mathrm{Hg}$ (Table 3b). Within this age group, age still entered significantly in the model and near VA loss was negatively associated with \%DHA. Entering \%DHA in the model increased the $\beta$ estimate for $\mathrm{Log} \mathrm{H}-\mathrm{Hg}$ by $50 \%$ and when Log B-Se was entered into the model, the $\beta$ estimate for $\mathrm{Log} \mathrm{H}-\mathrm{Hg}$ further increased by $12 \%$ although Log B-Se did not reach the significance level $(\beta=-0 \cdot 19$, $P=0 \cdot 15)$. Twenty-four per cent (24\%) of the variance of 
Table 3 Results of multiple linear regression models for visual acuity loss in the right eye, showing the $\beta$ estimates and their level of significance, among adults ( $n$ 243) from fish-eating communities of Tapajós River in the Brazilian Amazon

\begin{tabular}{|c|c|c|c|c|c|c|}
\hline \multicolumn{7}{|c|}{ a) Near visual acuity for all participants ( $n$ 241) } \\
\hline & M1 & M2 & M3 & M4 & M5 & M6 \\
\hline Age & $0 \cdot 016^{\star * \star}$ & $0 \cdot 016^{\star \star \star}$ & $0 \cdot 016^{\star \star \star}$ & $0 \cdot 016^{\star \star *}$ & $0 \cdot 016^{\star * *}$ & $0 \cdot 016^{\star * *}$ \\
\hline Sex & 0.009 & 0.014 & 0.010 & 0.014 & 0.015 & 0.016 \\
\hline Smoking & $-0.023 t$ & -0.021 & $-0.022 \dagger$ & -0.021 & -0.021 & -0.019 \\
\hline Drinking & 0.017 & 0.018 & $0.019 t$ & $0.022 t$ & $0.022 t$ & $0.025^{\star}$ \\
\hline Examiner & 0.005 & 0.007 & 0.006 & 0.018 & 0.018 & 0.015 \\
\hline Log $\mathrm{H}-\mathrm{Hg}$ & & $0.065^{\star}$ & $0.072^{*}$ & $0.098^{\star \star}$ & $0 \cdot 10^{\star *}$ & $0.095^{\star *}$ \\
\hline Log B-Pb & & & -0.024 & -0.023 & -0.021 & 0.0033 \\
\hline$\% \mathrm{DHA}$ & & & & $-0.040^{\star}$ & $-0.040^{*}$ & $-0.044^{* *}$ \\
\hline Log B-Se & & & & & $-0 \cdot 041$ & -0.042 \\
\hline Age $\times \log \mathrm{H}-\mathrm{Hg}$ & & & & & & $0.007^{\star *}$ \\
\hline
\end{tabular}

b) Near visual acuity for participants between 40 and 66 years $(n 92)$

\begin{tabular}{|c|c|c|c|c|c|}
\hline & M1 & M2 & M3 & M4 & M5 \\
\hline Age & $0.007^{\star}$ & $0.007^{(\star)}$ & $0.007^{(\star)}$ & $0.008^{*}$ & $0.008^{*}$ \\
\hline Sex & 0.024 & 0.032 & 0.0334 & $0.040^{(*)}$ & $0.044^{(*)}$ \\
\hline Smoking & $-0.048^{(*)}$ & -0.034 & -0.033 & -0.026 & -0.023 \\
\hline Drinking & 0.008 & 0.013 & 0.013 & 0.033 & 0.029 \\
\hline Examiner & 0.011 & 0.002 & 0.002 & 0.025 & 0.022 \\
\hline Log H-Hg & & $0 \cdot 18^{\star \star}$ & $0 \cdot 17^{\star}$ & $0 \cdot 25^{\star \star \star}$ & $0 \cdot 28^{\star \star \star}$ \\
\hline Log B-Pb & & & 0.017 & 0.0014 & 0.030 \\
\hline$\% \mathrm{DHA}$ & & & & $-0.095^{\star \star}$ & $-0 \cdot 10^{\star *}$ \\
\hline Log B-Se & & & & & -0.19 \\
\hline
\end{tabular}

c) Distant visual acuity for participants between 40 and 66 years $(n 92)$

\begin{tabular}{lccccc} 
& M1 & M2 & M3 & M4 & M5 \\
\hline Age & $0.014^{\star *}$ & $0.013^{\star *}$ & $0.013^{\star *}$ & $0.012^{\star *}$ & $0.012^{\star *}$ \\
Sex & $0.047^{(*)}$ & $0.053^{*}$ & $0.068^{\star *}$ & $0.066^{*}$ & $0.069^{\star *}$ \\
Smoking & -0.033 & -0.023 & -0.010 & -0.012 & -0.010 \\
Drinking & 0.026 & 0.030 & 0.025 & 0.019 & 0.016 \\
Examiner & 0.031 & 0.024 & 0.025 & 0.012 & 0.016 \\
Log H-Hg & & $0.13^{(*)}$ & 0.11 & 0.085 & 0.11 \\
Log B-Pb & & $0.18^{(*)}$ & $0.18^{(*)}$ & $0.19^{\star}$ \\
\%DHA & & & 0.031 & 0.027 \\
Log B-Se & & & & -0.13 & \\
\hline
\end{tabular}

$\mathrm{M}$, model; $\mathrm{H}$, hair; $\mathrm{B}$, blood.

Significance of the $\beta$ estimate: ${ }^{(*)} P<0 \cdot 10 ;{ }^{\star} P<0 \cdot 05 ;{ }^{* \star} P<0.01 ;{ }^{* \star} P<0.0001$.

near VA was explained by the final model; Log $\mathrm{H}-\mathrm{Hg}$ explained $6 \cdot 5 \%$ of the variance, while age explained $3.5 \%$. Similar results were found for the left eye.

In the group over 40 years of age, multivariate logistic regression analyses showed that, for the right eye, higher $\mathrm{H}-\mathrm{Hg}(\geq 15 \mu \mathrm{g} / \mathrm{g})$ was associated with increased odds of presenting clinical near visual impairment $(\mathrm{OR}=3.93$, $95 \%$ CI $1 \cdot 25,14 \cdot 18)$, whereas higher \%DHA ( $\geq 1$ st tertile concentration of $1 \cdot 88 \%$ ) was associated with better vision $(\mathrm{OR}=0 \cdot 37,95 \%$ CI $0 \cdot 11,1 \cdot 11)$. Similar results were obtained for the left eye.

The same process was followed for distant VA. In the entire study group, age, sex and examiner showed significant positive associations $(P<0.05)$ with distant VA in both eyes. For the right eye, there was a tendency for Log $\mathrm{B}-\mathrm{Pb}$ to be positively associated with distant VA loss ( $\beta=0.074, P=0 \cdot 08$ ) while none of the $n-3$ FA measures nor Log B-Se were significantly associated to distant VA. For $\mathrm{Log} \mathrm{H}-\mathrm{Hg}$, all of the estimates were in the positive direction but did not reach significance level $(P<0 \cdot 05)$. In the left eye, the association with Log B-Pb was not present. In both models, the interaction term between Log $\mathrm{B}-\mathrm{Pb}$ and age was not significant.

In the population between 40 and 66 years old, age and sex presented significant positive associations with distant VA loss (Table 3c). In the right eye, Log B-Pb showed a positive association with a decrease in distant VA $(\beta=0 \cdot 19, P=0 \cdot 05)$. Twenty-eight per cent $(28 \%)$ of the variance of distant VA was explained by the final model; Log $\mathrm{B}-\mathrm{Pb}$ explained $4.9 \%$ of the variance, while age explained $14 \cdot 6 \%$ and sex explained $3 \cdot 5 \%$.

For distant visual impairment among the older group, higher $\mathrm{B}-\mathrm{Pb}(\geq 10 \mu \mathrm{g} / \mathrm{dl})$ was associated with an adjusted OR for clinical moderate visual impairment of $5 \cdot 39$ (95\% CI $1 \cdot 10,34 \cdot 55)$. Similar results were found for the left eye.

\section{Discussion}

In this fish-eating population in the Brazilian Amazon, those under 40 years old presented good near and distant VA. Quite the opposite was observed for those between 
40 and 66 years old, who presented at least mild visual loss for near and distant VA (85\% and 55\%, respectively). Our findings suggest that after 40 years of age, near VA loss progresses more quickly with higher $\mathrm{Hg}$ exposure, while DHA may slow down this process. In this same age range, distant VA loss was associated with $\mathrm{Pb}$ exposure, but results were less consistent.

Presbyopia, the normal age-related loss of near VA, results from the eye's reduced ability accommodate and depends upon lens elasticity and ciliary muscle functioning ${ }^{(36)}$. It occurs around 40 years of age, develops relatively rapidly in the first decade and tends to stabilize around 60 years ${ }^{(37)}$. In the population investigated in the present study, presbyopia likewise began around 40 years old, but there was a fourfold increased risk for clinical near visual impairment for those with $\mathrm{H}-\mathrm{Hg}$ levels of $15 \mu \mathrm{g} / \mathrm{g}$ and higher.

$\mathrm{Hg}$ may contribute to the progressive decrease of power of accommodation by interfering with lens and/or ciliary muscle function. With ageing, the lens increases in size and becomes less flexible and transparent ${ }^{(38)}$. Some reports suggest that $\mathrm{Hg}$ accumulates in the lens and may be involved in cataract formation ${ }^{(39,40)}$. In a study of this Amazon population, those above 65 years old showed and a very high prevalence of age-related cataracts, with an Hg-related increase in risk ${ }^{(23)}$. Although persons with diagnosed cataracts were excluded from the present analysis, it is possible that the observed loss of near VA may be due to initial subclinical changes in the lens crystalline structure that conventional techniques could not identify. Hg may also interfere with some of the processes involved in the contraction of ciliary muscles. Both animal and human studies have demonstrated effects of $\mathrm{Hg}$ on motor functions ${ }^{(41)}$, but no study has specifically investigated ciliary muscles.

To our knowledge, the present study is the first to demonstrate that near VA is associated with DHA in adults. It has been suggested that dietary DHA is needed for the optimum functional maturation of the retina and visual cortex, with VA and mental development seemingly improved by extra $\mathrm{DHA}^{(42)}$. Several studies have established a link between prenatal DHA and visual functions ${ }^{(43-47)}$. The fact that DHA seems to play a role in near VA and not in distant VA suggests that DHA may influence ocular structures rather than the retina or visual cortex.

In the present study, Se did not appear to be protective for near VA loss. An experimental study in adult zebrafish showed that developmental co-exposure to selenomethionine could reduce $\mathrm{MeHg}$-induced visual deficits associated with visual responses to a rotating black bar under low light conditions ${ }^{(48)}$. It should be noted that there were few people with Se deficiency in the present population and it is possible that normal Se levels are sufficient to maintain visual functions. For age-related cataracts, in this same population, Lemire et $a l^{(21)}$ reported a synergistic effect of plasma Se and blood $\mathrm{Hg}$, with a prevalence OR of $16 \cdot 4$ (95\% CI 3.04, 87.9) for those with low plasma Se and high blood $\mathrm{Hg}$.

Our results suggest that distant VA loss may be associated to $\mathrm{B}-\mathrm{Pb}$ levels in these middle-aged people, in whom we observed a fivefold increase in the probability of presenting clinical moderate visual impairment at $\mathrm{B}-\mathrm{Pb}$ levels of $10 \mu \mathrm{g} / \mathrm{dl}$ or higher. Experiments on monkeys showed that selective lesions to the parvocellular pathway lead to deficits in distant $\mathrm{VA}^{(49,50)}$. Long-term developmental effects of $\mathrm{Pb}$ exposure on the visual system have been documented in animal models. Adult monkeys exposed to $\mathrm{Pb}$ pre- and postnatally showed a decrease in tyrosine hydroxylase in retinal neurons after a 35-month period of a $\mathrm{Pb}$-free diet, suggesting a persisting effect of $\mathrm{Pb}$ exposure on dopaminergic retinal amacrine cells ${ }^{(51)}$. In rats, high-level gestational $\mathrm{Pb}$ exposure produced rodselective toxicity, revealing the sensitivity and vulnerability of the developing retina to gestational $\mathrm{Pb}$ exposure ${ }^{(52)}$. In the present study, no association between distant VA and blood $\mathrm{Pb}$ was observed for participants under 40 years of age. For the older group, since $\mathrm{Pb}$ exposure in the study region was unknown until recently ${ }^{(16)}$, we do not know at what age exposure to $\mathrm{Pb}$ began, and whether the effect is due to cumulative, past or present exposure.

Since riverside people spend the major part of the day working outside, we also examined whether pterygia, a condition also known in this region as carne crescida and exacerbated by long-term exposure to sunlight (especially UV rays) and dust, influenced the results. As expected, the prevalence of pterygia was high in this population and increased with age, but it did not contribute to loss in near and distant VA in these mid-age people, nor did it affect the relationship between any of the biomarkers and VA loss.

The degree of age-related loss in distant VA in the present study is noteworthy. Although distant VA declines with age in people without any eye pathology, population studies indicate that the majority of people maintain at least a fair distant acuity (20/40 or better) into their $80 s^{(53,54)}$. It has been suggested that this decline cannot be attributed to optical changes and must therefore be due to changes in the retina or central visual pathway; however, anatomical studies in people and monkeys suggest that ageing has only relatively minor effects on the retino-geniculo-striate pathway ${ }^{(55)}$. In the present study, since people presenting with any type of ocular pathology were excluded from the analyses, it is not likely that the age-related visual impairments observed were of ocular pathological origin.

Although this was not a random sample and one cannot extrapolate the prevalence data from the present study to the entire population, it is interesting to compare the distribution of VA loss with data reported from other countries. The distribution of distant visual loss with age is different from that reported in the US National Health and Nutrition Examination Survey $(\text { NHANES })^{(54)}$, where 
$33 \%$ of persons under 40 years of age presented myopia $(\leq-0 \cdot 5 \mathrm{D}$ or $6 / 7 \cdot 5)$. In the present study, only $12 \%$ of the people below 40 years old presented myopia. For those over 40 years old, $41 \%$ in NHANES had myopia, while in this Amazonian population, 55\% presented with distant VA poorer than $6 / 7 \cdot 5$. This higher prevalence of VA deficits in the Amazon population could be due to their elevated $\mathrm{Hg}$ levels, but could also be due to a selection bias: participation rate for the older group may have been higher among those with poor vision compared with those who did not require visual corrections.

In the Brazilian Amazon, where people have a limited access to health services, visual impairment often remains uncorrected. Other authors from Brazil have already pointed out the uncorrected refractive errors as the main cause of visual impairment in Brazil ${ }^{(56)}$. In the present study, we were able to adequately refract $85 \%$ for near VA and $74 \%$ for distant VA. These findings support the assertion that uncorrected refractive errors are often overlooked and need to be assessed and reported as a cause of visual impairment ${ }^{(57)}$.

\section{Acknowledgements}

This work was financially supported by the Canadian Institutes of Health Research and the Fundação de Amparo à Pesquisa do Estado de São Paulo from Brazil; Health Canada provided the facilities for hair $\mathrm{Hg}$ analyses. There are no conflicts of interest. M.F. participated in the design of the study, conducted the fieldwork and data collection, analysed the data and wrote the manuscript. M.L. participated in the design of the study, participated to the fieldwork and data collection and reviewed the manuscript. A.P. participated in the statistical analyses and reviewed the manuscript. B.F. designed the visual system evaluation and reviewed the manuscript. H.A.W. designed the methods for analysing fatty acids in plasma phospholipids and reviewed the manuscript. J.R.D. analysed the fatty acids in plasma phospholipids and reviewed the manuscript. J.R.D.G. participated to the fieldwork and reviewed the manuscript. F.L. participated in the statistical analyses and reviewed the manuscript. F.B. analysed $\mathrm{Hg}$, Se and $\mathrm{Pb}$ in blood and urine samples and reviewed the manuscript. D.M. designed the study, analysed the data and participated in writing the manuscript. The authors are grateful to the villagers of the Tapajós region and to Marie-Ève Thibault for administrative work.

\section{References}

1. Lebel J, Mergler D, Branches F et al. (1998) Neurotoxic effects of low-level methylmercury contamination in the Amazonian Basin. Environ Res 79, 20-32.

2. Clarkson TW (1993) Mercury: major issues in environmental health. Environ Health Perspect 100, 31-38.
3. Murata K, Grandjean P \& Dakeishi M (2007) Neurophysiological evidence of methylmercury neurotoxicity. Am J Ind Med 50, 765-771.

4. Korogi Y, Takahashi M, Hirai T et al. (1997) Representation of the visual field in the striate cortex: comparison of MR findings with visual field deficits in organic mercury poisoning (Minamata disease). AJNR Am J Neuroradiol 18, 1127-1130.

5. Mukuno K, Ishikawa S \& Okamura R (1981) Grating test of contrast sensitivity in patients with Minamata disease. Br J Ophthalmol 65, 284-290.

6. Lebel J, Mergler D, Lucotte M et al. (1996) Evidence of early nervous system dysfunction in Amazonian populations exposed to low levels of methylmercury. Neurotoxicology 17, 157-167.

7. Stamler CJ, Mergler D, Abdelouahab N et al. (2006) Associations between platelet monoamine oxidase-B activity and acquired colour vision loss in a fish-eating population. Neurotoxicol Teratol 28, 446-452.

8. Stamler CJ, Abdelouahab N, Vanier C et al. (2006) Relationship between platelet monoamine oxidase- $\mathrm{B}$ (MAO-B) activity and mercury exposure in fish consumers from the Lake St. Pierre region of Que., Canada. Neurotoxicology 27, 429-436.

9. Berzas Nevado JJ, Rodriguez Martin-Doimeadios RC, Guzman Bernardo FJ et al. (2010) Mercury in the Tapajos River basin, Brazilian Amazon: a review. Environ Int 36, 593-608.

10. Passos CJ \& Mergler D (2008) Human mercury exposure and adverse health effects in the Amazon: a review. Cad Saude Publica 24, Suppl. 4, S503-S520.

11. Jeffrey BG \& Neuringer M (2009) Age-related decline in rod phototransduction sensitivity in rhesus monkeys fed an $n-3$ fatty acid-deficient diet. Invest Ophthalmol Vis Sci 50, 4360-4367.

12. Cakiner-Egilmez T (2008) Omega 3 fatty acids and the eye. Insight 33, 20-25.

13. Weisinger HS, Armitage JA, Jeffrey BG et al. (2002) Retinal sensitivity loss in third-generation $n$-3 PUFA-deficient rats. Lipids 37, 759-765.

14. Cheatham CL, Colombo J \& Carlson SE (2006) N-3 fatty acids and cognitive and visual acuity development: methodologic and conceptual considerations. Am J Clin Nutr 83, Suppl. 6, 1458S-1466S.

15. Calder PC \& Yaqoob P (2009) Omega-3 polyunsaturated fatty acids and human health outcomes. Biofactors 35 , 266-272.

16. Barbosa F Jr, Fillion M, Lemire M et al. (2009) Elevated blood lead levels in a riverside population in the Brazilian Amazon. Environ Res 109, 594-599.

17. Rice DC \& Hayward S (1999) Comparison of visual function at adulthood and during aging in monkeys exposed to lead or methylmercury. Neurotoxicology 20, 767-784.

18. Lemire M, Mergler D, Fillion M et al. (2006) Elevated blood selenium levels in the Brazilian Amazon. Sci Total Environ 366, 101-111.

19. Lemire M, Mergler D, Huel G et al. (2009) Biomarkers of selenium status in the Amazonian context: blood, urine and sequential hair segments. J Expo Sci Environ Epidemiol 19, 213-222.

20. Pinheiro MC, Muller RC, Sarkis JE et al. (2005) Mercury and selenium concentrations in hair samples of women in fertile age from Amazon riverside communities. Sci Total Environ 349, 284-288.

21. Lemire M, Fillion M, Barbosa F Jr et al. (2010) Elevated levels of selenium in the typical diet of Amazonian riverside populations. Sci Total Environ 408, 4076-4084.

22. Flohe L (2005) Selenium, selenoproteins and vision. Dev Ophthalmol 38, 89-102.

23. Lemire M, Fillion M, Frenette B et al. (2010) Selenium and mercury in the Brazilian Amazon: opposing influences 
on age-related cataracts. Environ Health Perspect 118, 1584-1589.

24. Head KA (2001) Natural therapies for ocular disorders, part two: cataracts and glaucoma. Altern Med Rev 6, 141-166.

25. CARUSO (2011) Mercury exposure and ecosystem health in the Amazon. http://www.unites.uqam.ca/gmf/caruso/ caruso_home.htm (accessed January 2011).

26. Passos CJ, Mergler D, Fillion M et al. (2007) Epidemiologic confirmation that fruit consumption influences mercury exposure in riparian communities in the Brazilian Amazon. Environ Res 105, 183-193.

27. Bastos WR, Malm O, Pfeiffer WC et al. (1998) Establishment and analytical quality control of laboratories for $\mathrm{Hg}$ determination in biological and geological samples in the Amazon - Brazil. Ciência e Cultura 50, 255-260.

28. Mergler D, Anderson HA, Chan LH et al. (2007) Methylmercury exposure and health effects in humans: a worldwide concern. Ambio 36, 3-11.

29. Farant JP, Brissette D, Moncion L et al. (1981) Improved cold-vapor atomic absorption technique for the microdetermination of total and inorganic mercury in biological samples. J Anal Toxicol 5, 47-51.

30. Palmer CD, Lewis ME, Geraghty CM et al. (2006) Determination of lead, cadmium and mercury in blood for assessment of environmental exposure: a comparison between inductively coupled plasma-mass spectrometry and atomic absorption spectrometry. Spectrochim Acta B 61, 980-990.

31. Batista BL, Rodrigues JL, Nunes JA et al. (2009) Exploiting dynamic reaction cell inductively coupled plasma mass spectrometry (DRC-ICP-MS) for sequential determination of trace elements in blood using a dilute-and-shoot procedure. Anal Chim Acta 639, 13-18.

32. Bondia-Pons I, Morera-Pons S, Castellote AI et al. (2006) Determination of phospholipid fatty acids in biological samples by solid-phase extraction and fast gas chromatography. J Chromatogr A 1116, 204-208.

33. West $S$ \& Munoz B (2009) Prevalence of pterygium in Latinos: Proyecto VER. Br J Ophthalmol 93, 1287-1290.

34. Bradley JC, Yang W, Bradley RH et al. (2010) The science of pterygia. Br J Ophthalmol 94, 815-820.

35. International Council of Ophthalmology (2002) Visual Standards - Aspects and Ranges of Vision Loss with Emphasis on Population Surveys. Sydney: ICO.

36. Noback CR, Strominger NL, Demarest RJ et al. (2005) The Human Nervous System: Structure and Function, 6th ed. Totowa, NJ: Humana Press.

37. Morgan MW (1986) Changes in visual function in the aging eye. In Vision and Aging: General and Clinical Perspectives, pp. 121-134 [AA Rosenbloom and MW Morgan, editors]. New York: Fairchild Publications.

38. Pokorny J, Smith VC \& Verriest G (1979) Physiological and theoretical bases of normal color vision. In Congenital and Acquired Color Vision Defects, pp. 57-70 [J Pokorny, VC Smith, G Verriest et al., editors]. New York: Grune \& Stratton.

39. Winder AF, Astbury NJ, Sheraidah GA et al. (1980) Penetration of mercury from ophthalmic preservatives into the human eye. Lancet 2, 237-239.

40. Gabal MS \& Raslan OA (1995) Ocular disorders among workers exposed to mercury. J Egypt Public Health Assoc 70, $1-14$.
41. Clarkson TW \& Magos L (2006) The toxicology of mercury and its chemical compounds. Crit Rev Toxicol 36, 609-662.

42. Uauy R \& Dangour AD (2006) Nutrition in brain development and aging: role of essential fatty acids. Nutr Rev 64, Pt 2, S24-S33.

43. Hoffman DR, Boettcher JA \& Diersen-Schade DA (2009) Toward optimizing vision and cognition in term infants by dietary docosahexaenoic and arachidonic acid supplementation: a review of randomized controlled trials. Prostaglandins Leukot Essent Fatty Acids 81, 151-158.

44. Malcolm CA, McCulloch DL, Montgomery C et al. (2003) Maternal docosahexaenoic acid supplementation during pregnancy and visual evoked potential development in term infants: a double blind, prospective, randomised trial. Arch Dis Child Fetal Neonatal Ed 88, F383-F390.

45. Hoffman DR, Theuer RC, Castaneda YS et al. (2004) Maturation of visual acuity is accelerated in breast-fed term infants fed baby food containing DHA-enriched egg yolk. J Nutr 134, 2307-2313.

46. SanGiovanni JP, Parra-Cabrera S, Colditz GA et al. (2000) Meta-analysis of dietary essential fatty acids and long-chain polyunsaturated fatty acids as they relate to visual resolution acuity in healthy preterm infants. Pediatrics 105, 1292-1298.

47. Jacobson JL, Jacobson SW, Muckle G et al. (2008) Beneficial effects of a polyunsaturated fatty acid on infant development: evidence from the Inuit of Arctic Quebec. J Pediatr 152, 356-364.

48. Weber DN, Connaughton VP, Dellinger JA et al. (2008) Selenomethionine reduces visual deficits due to developmental methylmercury exposures. Physiol Behav 93, 250-260.

49. Merigan WH, Katz LM \& Maunsell JH (1991) The effects of parvocellular lateral geniculate lesions on the acuity and contrast sensitivity of macaque monkeys. J Neurosci 11, 994-1001.

50. Merigan WH \& Eskin TA (1986) Spatio-temporal vision of macaques with severe loss of $\mathrm{P}$ beta retinal ganglion cells. Vision Res 26, 1751-1761.

51. Kohler K, Lilienthal H, Guenther E et al. (1997) Persistent decrease of the dopamine-synthesizing enzyme tyrosine hydroxylase in the rhesus monkey retina after chronic lead exposure. Neurotoxicology 18, 623-632.

52. Fox DA, Kala SV, Hamilton WR et al. (2008) Low-level human equivalent gestational lead exposure produces supernormal scotopic electroretinograms, increased retinal neurogenesis, and decreased retinal dopamine utilization in rats. Environ Health Perspect 116, 618-625.

53. Gittings NS \& Fozard JL (1986) Age related changes in visual acuity. Exp Gerontol 21, 423-433.

54. Vitale S, Ellwein L, Cotch MF et al. (2008) Prevalence of refractive error in the United States, 1999-2004. Arch Ophthalmol 126, 1111-1119.

55. Spear PD (1993) Neural bases of visual deficits during aging. Vision Res 33, 2589-2609.

56. Salomao SR, Mitsuhiro MR \& Belfort R Jr (2009) Visual impairment and blindness: an overview of prevalence and causes in Brazil. An Acad Bras Cienc 81, 539-549.

57. Resnikoff S, Pascolini D, Mariottia SP et al. (2008) Global magnitude of visual impairment caused by uncorrected refractive errors in 2004. Bull World Health Organ 86, 63-70. 